\title{
Escenarios del vacío y la desaparición. Ausencia y representación en Eco (Xacio Baño, 2015)
}

FERNANDO REDONDO NEIRA

\section{Resumen}

Integrado en el movimiento del Novo Cinema Galego, de cuyo carácter fronterizo participa, el filme Eco constituye una representación a la vez emotiva y reflexiva sobre las ideas de vacío, ausencia y desaparición. La lectura en pantalla de los diarios de la madre de uno de los protagonistas sitúa esta muestra de no ficción en una de las líneas más innovadoras del cine contemporáneo: la expresión de la subjetividad y la proyección exterior de determinados aspectos de la intimidad. El análisis fílmico procura comprender cómo las imágenes logran, con la concreción que les caracteriza y una sobriedad formal extrema, abordar la abstracción propia de las emociones.

Palavras-chave: ausencia, intimidad, sobriedad. 


\section{Cenários do vácuo e o desaparecimento. Ausência e representação visual em Eco (Xacio Baño, 2015)}

FERNANDO REDONDO NEIRA

\section{Resumo}

Integrado no movimento do Novo Cinema Galego, de cujo carácter fronteiriço participa, o filme Eco constitui ao mesmo tempo uma representação emotiva e reflexiva sobre as ideias do vácuo, ausência e desaparecimento. A leitura em écran dos diários da mãe de um dos protagonistas coloca esta amostra de não ficção numa das linhas mais inovadoras do cinema contemporâneo: a expressão da subjectividade e a projeção exterior de determinados aspectos da intimidade. A análise fílmica tenta compreender como as imagens conseguem, com a concretude que lhes caracteriza e uma sobriedade formal extrema, tratar da abstração própria das emoções. 


\title{
Scenes of emptiness and disappearance. Absence and visual representation in ECO (Xacio Baño, 2015)
}

\begin{abstract}
Integrated into the movement of Novo Cinema Galego and taking part of its borderline characteristic, the film Eco constitutes an emotional and reflective representation of the concepts of emptiness, absence and disappearance. The reading on the screen of the mother's diaries of one of the protagonists places this non-fiction sample as one of the most innovative strands of contemporary cinema: the expression of subjectivity and the external projection of certain aspects of intimacy. The film analysis tries to understand how images manage to, with the precision that characterizes them and an extreme formal sobriety, deal with the abstraction typical of emotions.
\end{abstract}

Keywords:

Absence, intimacy, sobriety. 

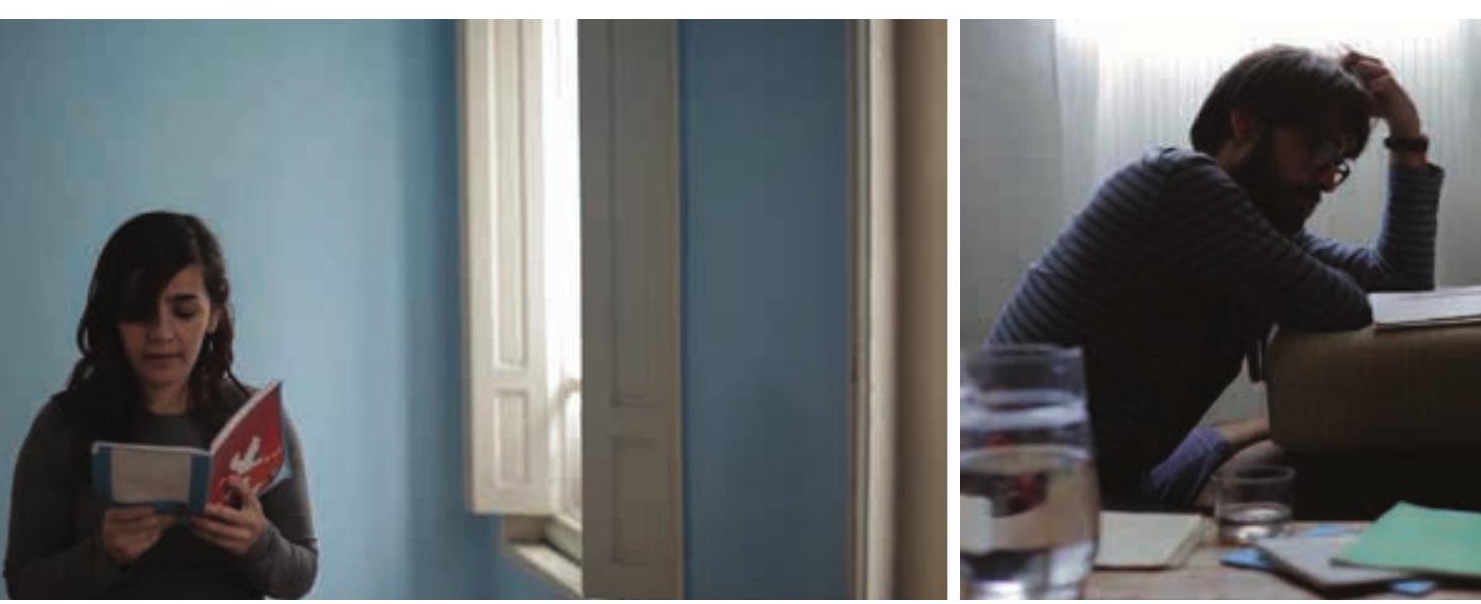

El filme Eco (Xacio Baño, 2015) presenta la particularidad de haber llevado hasta la máxima sobriedad formal la representación de un complejo discurso visual por el cual abordar cuestiones tan esenciales, y que aquí van remitiendo las unas a las otras, como la memoria familiar, la identidad, el devenir temporal, la desaparición o la muerte. Todo arranca de una mínima expresión de partida: los trabajos de una mudanza en una vivienda conducen al hallazgo de los diarios de la madre de uno de los protagonistas. De este modo, el asunto central de este mediometraje de no-ficción se sitúa en los parámetros propios de un discurso autobiográfico con el cual completar una historia de vida por medio de la lectura de aquel diario. Se otorga así voz a una figura silenciada por el tiempo y que ahora retoma el hilo de sus impresiones, reflexiones y frustraciones en el interior de esta propuesta minimalista de cuya puesta en imágenes se destila la idea de la ausencia y la fuerza emotiva de confesiones procedentes de lo más íntimo.

Visto su planteamiento de partida, conviene destacar que en Eco confluyen algunos de los trazos más característicos de un cierto cine contemporáneo, que se centra en la representación del yo y que, por tanto, busca orientar el discurso fílmico hacia una expresión de la subjetividad que bascula entre lo mostrado, lo sugerido y lo directamente ocultado. Nos proponemos, de este modo, realizar un análisis formal del citado filme, un análisis que indague en los mecanismos creadores de sentido y que seguirá un recorrido específico a través del cual poder deconstruir el dispositivo fílmico. Dicho recorrido se inspira en el propuesto por Casetti y Di Chio. Ambos 

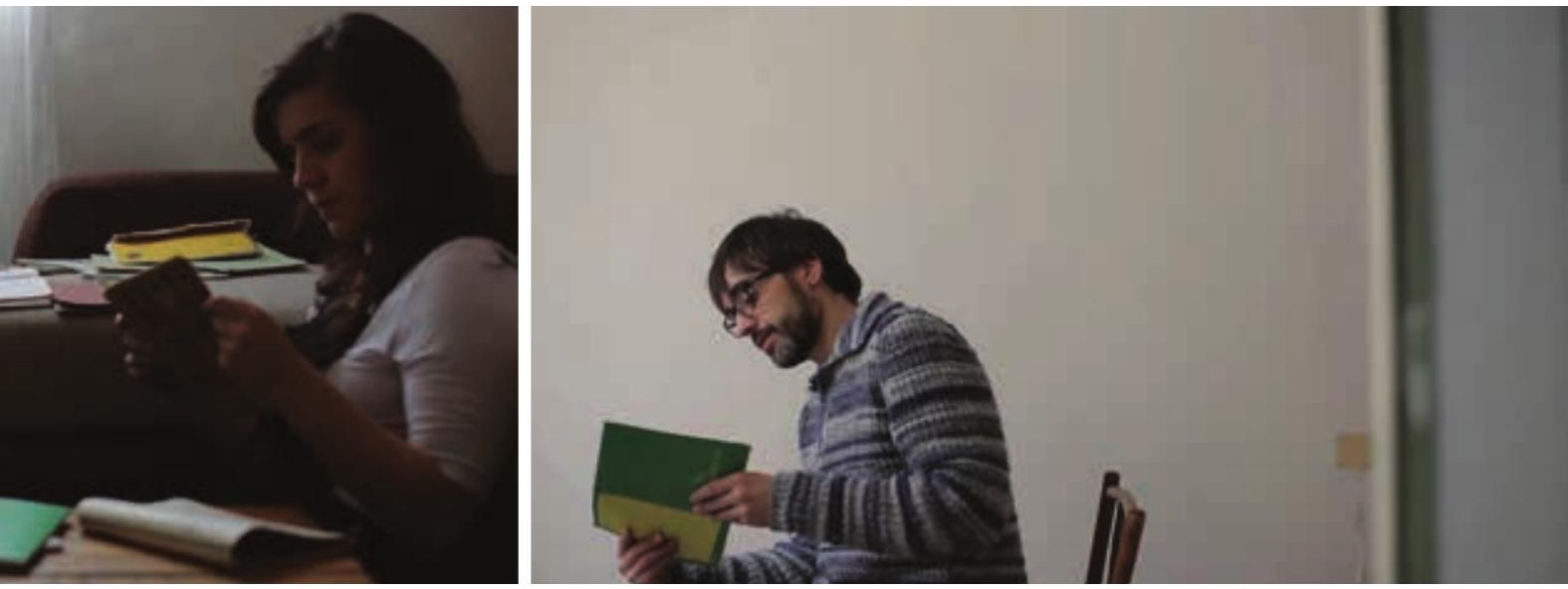

autores establecen tres niveles de artiulación fílmica: puesta en escena, referida a los contenidos de la imagen; puesta en cuadro, que alude a la disposición de dichos contenidos, es decir, a la composición y jerarquización de los elementos en campo; y puesta en serie, relativa al montaje o los nexos que se establecen entre las imágenes (CASETTI, DI CHIO, 1991, p. 126). Esta triple aproximación analítica actúa por descomposición y observación de las tres capas descritas para luego estudiar las conexiones que se establecen entre cada una de ellas, con lo que, finalmente, habremos de recomponer el armazón discursivo en su globalidad para alcanzar un mayor conocimiento de los recursos expresivos utilizados. Consideramos que el aquí descrito proceso metodológico se adapta especialmente a un filme como Eco, que, en el aspecto formal, se caracteriza por un progresivo vaciamiento de la imagen, una sobriedad y un minimalismo expresivos tales que logran así una más eficaz representación de la idea de la ausencia, un vacío vital que va desplegándose visualmente sobre la puesta en imágenes y que determina, en definitiva, su articulación en el interior del discurso fílmico.

\section{Novo Cinema Galego. Cine en/de la periferia}

En otro orden de cosas, y dado que no nos limitaremos a un análisis formal que se encierre en los estrictos límites del texto fílmico, nuestra propuesta buscará, a su vez, poner en relación dicho análisis con el contexto histórico y cultural en el que este filme se inscribe. Convencidos de 
que el propio tejido discursivo recoge ciertas huellas de este contexto, y que el análisis puede hacer emerger, este estudio buscará conectar, por tanto, lo que la película ofrece como tal con el marco social que la acoge. De este marco destacaremos un aspecto conformante que consideramos fundamental para comprender el filme en cuestión: el Novo Cinema Galego (NCG), movimiento cinematográfico en el que se integra $E c o$, que nace, de un modo oficioso y por indicar aquí una fecha de referencia, en 2010 (PAWLEY, 2010), y que venía a sumarse a otras propuestas semejantes de un cine que surge en los años más duros de la crisis económica y financiera iniciada en 2008. Integrado en un sistema audiovisual de dimensión reducida, tratándose de un cine periférico, situado en los márgenes de la industria dominante y que se expresa, en un número importante de sus títulos, en una lengua no hegemónica, el gallego, estas películas han logrado, no obstante, una fluida circulación por festivales y muestras internacionales. Han pugnado por encontrar su sitio, para lo cual han sabido usar a su favor el factor tecnológico, aquel que nos ha conducido en los últimos años hacia el escenario digital donde el acceso a las herramientas para la producción y la difusión audiovisual se ha democratizado en gran medida. Esto ha derivado, a su vez, en filmes caracterizados por una cierta factura artesanal, pero que, liberados de un pesado equipo técnico y humano, han podido salir adelante al margen del sistema industrial tradicional. Un segundo factor ha incidido en el desarrollo del NCG: el apoyo institucional que, sobre todo en los primeros años, ha proporcionado la Axencia Audiovisual Galega, dependiente de la Xunta de Galicia, que ha promovido la asunción de un modelo de producción viable en tiempos de crisis y, sobre todo, ha favorecido la emergencia de un talento creativo que fuera capaz de articular una mirada propia y diferenciada desde Galicia, su cultura y su lengua.

Hablamos, por tanto, de un cine periférico y en los márgenes, como ya venía indicado en un artículo publicado en Cahiers du Cinèma que otorgó visibilidad internacional al movimiento, si ésta no viniera dada ya de antemano por el galardón concedido en Cannes a Todos vós sodes capitáns (Olvier Laxe, 2010), premio FIPRESCI en el certamen francés. En aquel texto, de título revelador, "Loin de Madrid (AZALBERT, 2013), se hacía relación de los principales títulos del NCG y de los diferentes agentes que contribuyeron a su nacimiento, con especial refererencia a programadores y festiva- 
les, como es el caso del Play Doc de Tui. Entender lo fronterizo y lo periférico en tanto que rasgos transversales nos conduce a considerar, por un lado, la naturaleza de los discursos (especialmente la hibridación que se produce entre lo documental y lo ficcional) y, por otro, el modelo industrial que sostiene este cine y que, en el caso que nos ocupa, responde a unas estructuras mínimas o, directamente, a su ausencia y sustitución por modelos de autoproducción, de actuación cooperativa o de tipo artesanal; pero ello no impide, necesariamente, la visibilidad y proyección de las producciones del NCG: "Instalados na periferia ou no cine experimental, están a facer da nosa cultura un referente internacional con intereses en distintas partes do mundo, como forte contraposición ao que o sistema industrial galego viña realizando ao longo da súa historia" (SUÁREZ, 2014, p. 125). Dicho de otro modo: "Cine periférico puesto que se mueve al margen, a través de las brechas de la industria audiovisual” (ROMERO, 2015, p. 15). Es este, por tanto, un cine fronterizo y periférico, pero también pequeño y pobre, de escasas inversiones y equipamientos, lo cual, paradógicamente, va a favorecer que pueda salir adelante en tiempos de incertidumbre económica. Un cine pobre, también, en el sentido que le otorga Jean-Louis Comolli. Afirma el crítico y pensador francés que esta idea de pobreza no implica hablar de miserabilismo, pues lo que importa es, en primer lugar, la relación justa entre el gesto artístico y el gasto que implica (COMOLLI, 2007, p. 6o6). En el diccionario-ensayo que años después elabora con Vincent Sorrel retomará este concepto para señalar: "cuando no se tiene nada o se tiene muy poco, el desafío artístico es mayor y la abundancia evita pensar" (COMOLLI, SORREL, 2016, P. 269). Finalmente, lo que el NCG representa realmente, y la película que aquí analizamos se ajusta a ello, lo ha resumido muy bien Isabel Martínez en su tesis doctoral sobre este movimiento cinematográfico: la digitalización, el amateurismo (tal como lo reivindicaba Flaherty, a decir de la autora, en tanto que portador de arte y verdad), la autoproducción y la cinefilia, entendida esta en los siguientes términos: "un achegamento ao cine afastado da postura academicista, de mirada experta, que se realiza dun xeito informal e que se move pola pura paixón ou as gañas de coñecer, así como polo interese de descubrir outras miradas e formas de entender o mundo" (2015, p. 140).

La disponibilidad tecnológica que hoy parece poder hacer realidad la vieja pretensión de Alexander Astruc de la camera-stylo, expresión que ha hecho fortuna para referirse 
a un cine espontáneo, libre, personal y desprovisto de pesadas estructuras industriales, se une en títulos como Eco a la tendencia que los filmes de no ficción vienen desarrollando por discursos dirigidos a lo subjetivo y lo íntimo, así como a la ocupación del territorio de lo privado llevado a cabo por cineastas provistos de equipos ligeros para la captación de la imagen y el sonido. El afán por la autoexpresión ha invadido ya buena parte de las últimas modalidades de la comunicación, desde la interacción constante en las redes sociales a los vídeos en YouTube u otras plataformas, a través de los cuales llevar un registro prácticamente ininterrumpido de, casi siempre, banales momentos de la existencia cotidiana. Esto deriva en múltiples cambios relativos a nuestros modos de relación social y de estar en el mundo: "La sociedad ha hecho que cada uno se defina por la mirada del otro, dificultando la posibilidad de refugiarse en uno mismo y de enfrentarse a la soledad" (MAMBLONA, 2015, p. 99). Mamblona señala, no obstante, que, pese a abrirse a nuevas manifestaciones de la realidad, el documental aún no se ha entregado a esta adhesión por el desnudo incontrolable y desordenado de la vida privada (2015, p. 100). En este sentido, el autor prefiere recurrir al concepto de extimidad, que se contrapone al de intimidad y que hace referencia a aquellos aspectos que se hacen públicos, pese a parecer que están dentro de los límites de lo privado (2015, p. 99). Lo cierto, tal y como admite el propio autor, es que el documental contemporáneo actúa como poderosa herramienta de proyección y exteriorización de la intimidad (2015, p. 102). ¿Cómo se sitúa Eco en este panorama en el que confluyen lo íntimo y su expresión, el vértigo de lo cotidiano y la necesidad de su comunicación al exterior?

\section{Eco: una proyección de la intimidad}

El propio título hace referencia a la particular proyección de la intimidad que aquí se produce: la lectura de los diarios de la madre del protagonista masculino a cargo de éste y de su pareja. Las voces de ambos lectores constituyen, de este modo, una suerte de eco de aquella voz primera volcada en la escritura de unos cuadernos que salen ahora a la luz tras varios años ocultos. La reconstrucción de la memoria familiar que aquí se da, y en lo que ello tiene de conformación de la propia identidad supone, por otro lado, uno de los rasgos característicos de algunos de los títulos más notables del NCG. Sin ir más lejos, así ocurrí en otro título de Xacio Baño, Ser e voltar 
(2014), un viaje fílmico a la aldea originaria del cineasta para hacer un retrato de los abuelos y confrontarlos con su trabajo en las películas, ya respondía a este mismo afán. Allí figuraba, también, el esfuerzo dirigido a la permanencia de lugares, objetos y, sobre todo, personas (los abuelos) sometidas a los avatares del devenir temporal. Como bien ha explicado Laia Quilez, estamos asistiendo a una explosion de la memoria en el mundo occidental contemporáneo, "que contrasta y al mismo tiempo se explica por la valoración de lo caduco, lo fugaz, lo efímero y lo fragmentario" (2008, p. 85).

El tema de la memoria y su reconstrucción, como también el del paso del tiempo y, en este caso, su consecuencia principial, la ausencia, emergen ya en una aproximación analítica que explore el primero de los niveles de articulación fílmica: la puesta en escena. En el interior de una vivienda, tres personas llevan a cabo una mudanza. El piso se va quedando vacío, sin elementos decorativos ni prácticamente muebles, con las paredes desprovistas de carteles o cuadros, nada más que unas cajas para guardar y embalar objetos y unas sillas que ya solo se usan para sentarse a leer los diarios de la madre de uno de los protagonistas, la madre real del acto Xosé Barato, que aquí se interpreta a sí mismo. Esos cuadernos son ya lo último que se recoge de una casa que se abandona y las tareas de la mudanza se detienen para poder leer los diarios. La desnudez de la propia puesta en escena se conecta, así, con esa otra desnudez del alma que se refleja en los escritos de la madre, con alusiones a su resignación en una vida familar que solo le ofrece pesadumbre, salvo en las referencias hechas a los hijos, y que parece abocarla a una soledad que remite, a su vez, a esta otra soledad de ser estos, los diarios, los últimos objetos de un hogar que desaparece. El piso se vacía como se está vaciando el alma de la autora de estos diarios y el decorado, desprovisto ya de todo lo que recuerda a un lugar para vivir, apunta a un paisaje emocional igualmente desnudo. El final de una vida tal y como se ha desarrollado en esa casa conecta, entonces, con el principio, narrado también en los diarios, en los que se nos informa que, entonces, tampoco había muebles y se producía, antes como ahora, un mismo sentimiento de desolación.

Eco constituye finalmente la representación de una ausencia, la poderosa ausencia de la madre a la que, por un comentario del hijo, sabemos muerta pero cuyas impresiones, lamentos y reflexiones ocupan todo el espacio. $\mathrm{Ni}$ siquiera es su voz física, pero allí siguen sus pensamientos 
escritos años atrás y que han encontrado ahora a un destinatario, probablemente el primero después de la propia autora. Ella es entonces la verdadera protagonista del filme, un ser ausente que, sin embargo lo llena todo, precisamente en un lugar donde no hay ya prácticamente nada. Hablaríamos, de este modo, de un campo vacío, tal y como lo ha estudiado Daniela Musicco, pero habitado por una ausencia que pugna por hacerse notar: "Cuando alguien desaparece o está ausente, uno de los sentimientos más inmediatos en quienes le echan de menos es precisamente la percepción de su ausencia en el espacio" (2007, p. 17).

En esta deriva progresiva hacia la nada que representa Eco, surge así una segunda trama documental que se va desprendiendo de la primera hasta alcanzar entidad propia y que alcanza una presencia plena una vez que en campo ya solo quedan los cuadernos y algunos de sus textos sobreimpresionados. Las voces de los lectores convocan, de este modo, a la figura de la madre, quien comparece como protagonista principal y sugiere sin mostrar, pero haciéndolo igualmente presente de una forma poderosa, todo un recorrido vital que ahora se desvela en su desnuda intimidad. Sabemos de su llegada al piso vacío, del matrimonio desdichado, del marido ausente (en una suerte de mise en abyme que acumulara una ausencia doble), de los trabajos y pesares diarios, las soledades y el ansia por escribir. Al final, la verdadera película es ésta: la que se contiene en los diarios leídos. En su recorrido analítico por el Novo Cinema Galego, Víctor Paz aborda Eco en estos mismo términos: "O realizador confere poder à palavra porque sabe que nela está a força do relato, assim que se destitui de tudo mais" (2016, p. 15). Y añadirá, a continuación, otra idea fundamental para comprender el alcande de este filme: el haber concedido un espacio singular a las mujeres víctimas de la indiferencia, la reivindicación de nuevos espacios de representación para todas esas mujeres que se han sentido desplazadas durante tanto tiempo (PAZ, 2016, p. 15).

El mecanismo narrativo, pese a esta aparente sencillez, logra, sin embargo, construir un relato dotado de una temporalidad densa y compleja, que acoge la idea de duración, de los años transcurridos, pero también la de periodicidad en la regularidad de la redacción de los textos y en la reiteración de los conflictos que describe. La erosión del tiempo alcanza una plena visualidad en la propia apariencia física de los cuadernos y en la caligrafía cuidada y adornada propia de otras épocas. El trazo de la letra en la pantalla, pues va a ocupar finalmente el 
espacio pleno del encuadre, una vez abandonado el cuaderno original, adopta, además, la condición de metáfora de las heridas del tiempo. Difícilmente poder expresar otra cosa cuando el sentido de lo escrito alude a la rutina, la derrota y la amargura. La película que no está, pues no vemos en su literalidad nada de lo que escuchamos, es la que finalmente se impone, dando así vía libre a la labor más esencial que desempeña toda imagen que es hacer visible lo invisible. También un segmento fundamental del cine contemporáneo se mueve en estos parámetros, los del vacío y del tiempo destructor, como con tanta lucidez ha sabido explicar Doménec Font: "Allí donde la imagen desaparece, la representación mental toma el relevo. Las películas guardan la debilidad de las enfermedades del tiempo, de los excedentes de la memoria - sus intermitencias y quebraduras internas - y del olvido en la que aquella arriesga fundirse" (2012, p. 285).

Las confesiones íntimas vertidas en el diario van adquieriendo todo el protagonismo a medida que el piso se vacía. Su lectura es la tarea última que se propone llevar a cabo la pareja protagonista antes del inminente abandono de la vivienda. Y cuando ya no quedan muebles ni objetos por embalar, es la voz del pasado la que se impone sobre todo lo demás. En el nivel articulatorio de la puesta en cuadro, la composición del encuadre alterna los planos amplios de pasillos vacíos o paredes blancas, con alguna foto familiar enmarcada y colgada, con los primeros planos o planos medios de los protagonistas, casi siempre de larga duración y seguidos de significativos silencios. Y así, la lectura continúa sobre un plano fijo del largo pasillo, desnudo ya, como detenido en el pasado, creando también la sensación de que dicha voz viene, efectivamente, de ese pasado, o de que ha tomado posesión de un espacio que, al fin, solo a ella le pertenece; o bien con la chica sentadas de espaldas a cámara, otorgando aún más presencia a esta otra mujer que no está pero permanece a través de lo escrito en tantos cuadernos. En otro momento, el protagonista, uno de los hijos de la autora de los diarios, como se ha apuntado en otro lugar, se mantiene en un plano medio fijo mientras escucha el desgranar de las confesiones de la madre, precisamente el referido a su supuesto embarazo. Después, se nos muestra a la lectora, sentada en una silla, único mueble que queda ya, en un plano general reencuadrado en el marco de una puerta. En todos estos casos, la voz de la lectura suena bajo el efecto de un eco producido por la falta de muebles, de cajas de embalar o de los otros objetos que aparecían al 
principio, y que habíamos visto retirar en ciertos segmentos tomados a contraluz, con mucha sombra en los primeros términos, tal que fueran recuperados de un espacio olvidado. Y asimismo, los testimonios contenidos en los diarios proceden de esta misma zona de sombra, son descubiertos y sometidos al escrutinio de la luz y la lectura, y que ahora, sin la compañía de los objetos que le acompañaron en estos años del olvido, suena con este eco tan característico que da título a la película. Se proyecta sobre las paredes vacías y sobre el rostro del hijo, viaja desde el pasado en el que estas confesiones fueron escritas y se apoderan de todo el espacio fílmico.

Si las imágenes de archivo procedentes de un registro doméstico y familiar poseen, con el paso del tiempo, una innegable condición espectral, esta misma sensación se logra en Eco, si bien aquí se va a manifestar en la lectura de los diarios. El regreso de la madre muerta (y cabe deducir que está muerta, pues su hijo asegura que ya no renovaría el carnet de identidad) se produce por medio de las voces de prestado que leen lo que ha escrito. La puesta en serie se configura, de este modo, en un progresivo devenir hacia el interior de estos cuadernos. De lo general a lo particular, de la casa a los lectores y de los lectores al propio cuaderno, para terminar con las hojas sueltas que se suceden en la parte final del filme, con algunos pasajes que se destacan sobreimpresionados en la pantalla. Concluye así un programa discursivo que se iniciaba con lo mínimo y finaliza con lo esencial. Tratando siempre de evitar aquellos elementos que distraigan la atención de lo que importa, como ya figura en el primero de los planos de la película: un grupo de objetos arrinconados en el margen inferior izquierdo del encuadre, dejando libre todo lo demás para que sobre este vacío resuenen los pensamientos y las tribulaciones de la madre. El vacío es necesario para que el testimonio de lo escrito años atrás irrumpa ahora con toda su fuerza.

No siendo en sentido estricto un filme narrativo, la progresión secuencial sí que conforma, finalmente, un relato sobre la aniquilación y la muerte. El mencionado carácter espectral vampiriza literalmente el conjunto del filme. El 1 crítico e historiador Jaime Pena destacó en el marco del seminario "Pensando o Novo Cinema Galego, organizado por el Centro de Estudios Fílmicos de la Universidad de Santiago en setiembre de 2017, que el filme busca borrar todo efecto narrativo para quedarse con la esencia, de modo que primero desaparecen los actores, luegos las voces y solo quedan algunos textos destacados sobre la pantalla. Señala, además, que 
estamos ante una película que ha sabido sintetizar muchas corrientes contemporáneas del cine, y que, concretamente, se sitúa en la línea expresiva de la esencialidad y la emotividad que caracteriza a las películas de Straub y Huillet. Pena menciona, a su vez, un título fundamental para comprender la modernidad cinematográfica como es L'Aventura (Michelangelo Antonioni, 1960), donde también se busca sacar a la luz lo intangible, donde también todo parte de una desaparición y del vacío que deja a sus espaldas, tal como ha sabido analizar Doménec Font en su monografía sobre Antonioni al señalar que lo que aquella película pone en imágenes no es el intento de encontrar a la chica desaparecida, "sino en seguir el sinuoso trayecto afectivo que esta invisibilidad promueve" (FONT, 2003, P. 52).

Es en virtud de rasgos como estos, los que reúnen, en este caso, a Antonioni con Straub, los que hacen de Eco una singular muestra del Novo Cinema Galego, que hemos caraterizado de fronterizo, como aquí se demuestra en el sentido de haber sabido transitar entre la emoción y el pensamiento con el sencillo recurso a la lectura de unos textos. La citada carga emotiva se nutre, primeramente, del dolorido testimonio de la mujer que escribe y su dolor se proyecta sobre aquella puesta en escena del vacío de una vivienda, metáfora elocuente de una desolación vital, como también resuena en los primeros planos del hijo, que lee o escucha, ensimismado y reflexivo, volcado sobre unos diarios en los que, según asegura, no se habla demasiado de él, pero que sí le conciernen directamente y, sin duda, contribuyen a hacerse comprender mejor a sí mismo, su identidad y su historia. El pensamiento, por su parte, lo proporciona el distanciamiento que proporciona toda lectura. Y puesto que no estamos exactamente ante un diario fílmico, sino ante la filmación de la lectura de un diario, el hecho de no ver nunca a la autora de los textos ni escuchárselos leer propicia la apertura de un espacio de reflexión que nos permite afrontar al otro y a sus circunstancias sin la contaminante identificación emocional que supondría ponerle un cuerpo, una cara y una voz propios. El recitado como ejercicio de pensamiento y distancia ante lo mostrado se relaciona, por tanto, con la mencionada influencia straubiana.

Caracterizábamos también al principio al Novo Cinema Galego como un "cine pobre”. Pues bien, Eco recoge en su propio despliegue expresivo esta idea de pobreza, ya no solo en medios y recursos técnicos que, con los que se supone que aquí se utilizan, queda de manifiesto que se trata de los 
estrictamente necesarios. También, y sobre todo, por seguir la máxima de Comolli de que lo que importa es la relación justa entre gesto artístico y gasto que implica. Conviene hacer notar, entonces, de qué modo se corresponde aquello que se quiere mostrar o contar con los recursos (expresivos y técnicos) que se utilizan. Recordemos que el filme convoca la presencia de una figura ausente, la madre que se expresa a través de lo que ha dejado escrito; que busca representar lo intangible, algo tan alejado de lo concreto que una imagen pueda designar como las ideas de ausencia, de vacío, de desaparición y de muerte. Estamos, no lo olvidemos, en el territorio de lo esencial, en el núcleo original desde el cual explicar el verdadero alcance de lo que implica la representación visual: la presencia de lo ausente. Para lograrlo, en Eco no se requiere más que un único espacio (un piso que se va vaciando), dos personajes (tres, al principio) que leen unos cuadernos, una situación sencilla para poner en marcha la acción (los trabajos de una mudanza). La puesta en escena se reduce a ir mostrando un escenario que desaparece, la planificación se detiene en los rostros que leen o escuchan y en la visión de pasillos y paredes vacías y el montaje, finalmente, se limita a disponer una secuencialidad de las imágenes que conducen el devenir fílmico hasta la extinción, cuando ya solo quedan los textos de la madre.

\section{BIBLIOGRAFÍA}

Azalbert, N. (2013) Loin de Madrid: le cinéma galicien. Cahiers du cinema. no 693, 2013. 58-59.

Casetti, F. \& Di Chio, F. (1994). Cómo analizar un film (2ª ed.). Barcelona: Paidós.

Comolli, Jean-Lous (2007). Ver y poder. La inocencia perdida: cine, televisión, ficción, documental. Nueva Librería: Buenos Aires. P. 606.

Comolli, Jean-Lous; Sorrel, Vincent (2016). Cine, modo de empleo. De lo fotoquímico a lo digital. Manantial: Buenos Aires.

Font, Doménec (2003). Michelangelo Antonioni. Madrid: Cátedra. Font, Doménec (2012). Cuerpo a cuerpo. Radiografía del cine contemporáneo, Barcelona, Galaxia Gutemberg.

Mamblona, Ricard, "Viajes de identificación personal en el documental contemporáneo. De los autorreferencia a lo personal”. En Marta Álvarez, Hanna Hatzmann, Inmaculada Sánchez Alarcón (Eds.), No se está quieto. Nuevas 
formas documentales en el documental hispánico, Madrid, Iberoamericana, 2015, pp. 97-111.

Martínez Martínez, Isabel (2015). O cine de non ficción no Novo Cinema Galego (2006-2012): conceptualización, contextos e singularidades. Tesis Doctoral. Universidad de Vigo. Facultad de Ciencias Sociales y de la Comunicación. Disponible en: <http://novocinemagalego.info/wp-content/ uploads/2015/12/O_cine_de_non-ficcion_no_Novo_ Cinema_Galego-2006-2012.pdf > . Consulta: 18/12/2017.

Musicco Nombela, Daniela (2007). El campo vacío. El lenguaje indirecto en la comunicación audiovisual, Madrid: Cátedra.

Pawley, Martin (2010). 2010: o ano do novo cinema galego, Xornal de Galicia, 2 de xaneiro.

Paz Morandeira, Víctor (2016). Novo Cinema Galego: identidade e vangarda, México D.F.: La Internacional Cinematográfica / Los Cuadernos de Cinemazz.

Quílez, Laia (2008). "Sutiles pretéritos. (Post)memoriay (auto) biografía(s) en el cine documental contemporáneo"En Gregorio Martín Gutiérrez (edt.). Cineastas frente al espejo. Madrid: T\&B Editores.

Romero Suárez, Brais (2015): "Idioma e identidad en el Novo Cinema Galego". En Fonseca, Journal of Communication, 2015, 11, pp. 9-31.

Suárez, Pablo. "O Novo Cinema Galego. Galiza na senda da vangarda”. En Madrygal. Revista de estudos galegos, 2014, 17, pp. 123-130. 


\section{FERNANDO REDONDO NEIRA}

fernando.redondo@usc.es

Licenciado en Ciencias da Información pola Universidade do País Vasco (UPV) e Doutor pola Universidade de Santiago de Compostela (USC). Profesor na Facultade de Ciencias da Comunicación na área de Comunicación Audiovisual da USC. Autor do libro Carlos Velo. Itinerarios do documental nos anos trinta, editor e coordinador do volume Documental e Cidadanía Membro da Asociación Española de Historiadores do Cine (AEHC) e da Asociación Galega de Investigadoras e Investigadores da Comunicación (AGACOM). 